\section{La gráfica urbana como comunicación: macromural La Mariposa, Bogotá}

\section{Urban graphics as communication: macro mural La Mariposa, Bogotá}

https://doi.org/10.18566/comunica.n45.a06

Recibido: 20 de febrero de 2021

Aceptado: 31 de mayo de 2021

\section{Resumen}

Este trabajo se centra en el análisis de las prácticas comunicativas que se presentan en la gráfica urbana de los barrios que conforman el macromural de La Mariposa en Bogotá, atendiendo a la forma en que los murales y grafitis del sector, creados y desarrollados dentro del proyecto Habitarte durante la alcaldía de Enrique Peñalosa (2016-2019), lograron expresar un lenguaje y una cultura propios de la comunidad; es decir, aquello que quería decir en sus paredes en relación con las dinámicas y realidades de su territorio. Adicional a esto, también busca vincular estas prácticas con la dimensión teórica de la gráfica popular y urbana, la dialéctica de la lucha cultural, los espacios despolitizados y la perspectiva entre la estética oficial y la no oficial, desde un análisis de la configuración de ciudades modernas y los proyectos institucionales con trabajo colaborativo que generaron esta intervención. Esto con el fin de identificar cómo la comunidad se relaciona con su entorno y cómo el grafiti y el arte urbano en general se vuelven un mecanismo para expresar aquello que tanto los habitantes como la institucionalidad quieren comunicar dentro del territorio, gracias a lo cual terminan gestando procesos de apropiaciones, reflexiones y resignificaciones de lo comunicado.

\section{Abstract}

This work focuses on the analysis of the communicative practices that are presented in the urban graph of the neighborhoods that make up the macro mural of La Mariposa in Bogotá. Taking into account the way in which the murals and graffiti of the sector, created and developed during the "Habitarte" project during the Mayor's Office of Enrique Peñalosa, managed to express a language and culture typical of the community, referring to comunicación

número 45

Julio - diciembre

2021 | pp. 64-72

María José

Rodríguez González

Profesional en Ciencias

Políticas y estudiante

de maestría de Estudios

Culturales Latinoamericanos

de la Pontificia

Universidad Javeriana.

mariajoserodriguezg2@

gmail.com

https: / / orcid.org/0000-

0002-7841-2887 
what it wanted to express in its walls and in relation to the dynamics and realities of the territory. In addition to this, the work also seeks to relate these practices, with the theoretical dimension of popular and urban graphics, the dialectic of cultural struggle, depoliticized spaces and the perspective between official and unofficial aesthetics, from an analysis of the configuration modern cities and institutional projects with collaborative work, which generated this intervention in the city. This in order to identify how the community relates to its environment, and how graffiti and urban art become a mechanism to express what both the inhabitants and the institutions want to communicate within the territory and that end up generating processes of appropriations, reflections and resignifications of what is communicated.

\section{Introducción}

La aparición de las grandes ciudades en América Latina a partir del siglo XVI (Chaparro, 2011, p. 81) llevó a repensar la idea de la construcción de la estética de estos grandes centros urbanos, basados en la estructura y configuración del antiguo continente ${ }^{1}$ (las ciudades se empezaron a concebir desde la cultura europea). Pero las dinámicas y los rituales de la cotidianidad trajeron consigo un nuevo paisaje urbano. Para mediados de la década de los 70 se formalizó el arte urbano en Bogotá gracias a la Facultad de Arte de la Universidad Nacional de Colombia, "donde los artistas pintaban murales expresando sus pensamientos políticos y estéticos, con la influencia del Dadaísmo; sus grafitis eran juegos de palabras, imágenes con un sentido satírico, además de mensajes de justicia, [y] paz" (Cortés, 2017, p. 4).

En América Latina no fue donde se creó la gráfica urbana y popular, pero sus luchas particulares han marcado un estilo, un lenguaje y una comunicación propia de las dinámicas de los territorios. Por esta razón, es relevante plantearse estas preguntas: ¿qué es lo popular?, ¿cómo encaja el arte urbano con lo popular? Sin ánimo de romantizar, sino de expresar el rol que este desarrolla en la historia. Néstor García Canclini (1990) dice:

Lo popular es en esta historia lo excluido: los que no tienen patrimonio, o no logran que sea reconocido y conservado; los artesanos que no llegan a ser artistas, a individualizarse, ni participar en el mercado de bienes simbólicos "legítimos", los espectadores de los medios masivos que quedan fuera de las conversaciones y los museos, "incapaces" de leer y mirar la alta cultura porque desconocen la historia de los saberes y los estilos (1990, p. 191).

\section{Palabras clave}

Gráfica urbana, Estética, Comunicación popular, Subalterno, Proyectos institucionales.

\section{Key words}

Urban graphics, Aesthetics, Popular communication, Subordinate, Institutional projects.
1 "Las ciudades aseguraron la presencia de la cultura europea, dirigieron el proceso económico $y$, sobre todo, trazaron el perfil de las regiones sobre las que ejercían su influencia" (Romero, 2001, p. 9, citado en Chaparro, 2011, p. 81). 
En relación con esta definición de García Canclini, es importante atender las dinámicas de la gráfica urbana, la representación simbólica y de comunicación que forma parte de lo popular; es lo que se busca recuperar, esa expresión visual que en últimas refleja la relación con el entorno. La gráfica urbana se mantiene muchas veces en el relato no oficial porque no pretende ser parte de los discursos legítimos ni de una globalización de las ideas y la estética.

Un ejemplo de esa expresión visual es Bogotá, rodeada de un paisaje gráfico abundante: el graffiti, el muralismo, el arte urbano, etc. Algunos están allí para comunicar vivencias de lo popular, mientras otros, por distintas dinámicas y saturaciones visuales, no tienen tanta atención de los habitantes de la capital. La gráfica urbana y popular siempre ha tenido una carga de resistencia, comunicación y transformación del orden social, ya que puede crear y reproducir nuevos discursos y lenguajes. Así lo explica Popular de Lujo² (2011):

Las modalidades y ritmos que describe esta gráfica dan cuenta de numerosas prácticas urbanas: de sus modos de comercio, de las diferencias sociales, de la presencia de inmigrantes, de su nivel de desarrollo, de su cultura ciudadana, de su humor, etc. Por otra parte, esta gráfica es útil como radiografía de la ciudad, sirve también de radiografía de sus habitantes: ofrece señales culturales. Por alguna razón, esta gráfica no puede escapar del sello de quien la produce, de quien la encarga o la consume (2011, p. 2).

Estas prácticas urbanas, que se visibilizan e invisibilizan constantemente en lo popular, son parte de las dinámicas del espacio público con varias formas de acción y dependen mucho de lo que quieren expresar o, por el contrario, ocultar. Aun así, los dos casos comunican la manera en la que se habita en el entorno.

La gráfica urbana en Bogotá ha tenido un proceso interesante, que ha querido fomentar la institucionalidad. Durante el siglo XX en Colombia, y específicamente en la capital, se empezaron a planear proyectos desde la gráfica urbana, pero con intervención del distrito y de la empresa privada, en los barrios populares, un aspecto que en principio rompió con la dinámica de lo popular y la representación de la gráfica urbana. Entonces, parte del análisis implica entender qué es lo que se quiere comunicar por medio de la gráfica urbana en estos proyectos.

El proyecto del macromural de La Mariposa empezó en 2016 con el nombre Desmarginalizar y el objetivo, en teoría, de cambiarle la cara a la ciudad mejorando la estética de varios barrios populares. El proyecto quedó en pausa por un poco más de un año y en 2018 fue retomado con el nombre de Habitarte,
2 Organización sin ánimo de lucro que promueve el capital gráfico y cultural callejero en Bogotá. 
porque por medio de la pintura, el arte urbano y el trabajo comunitario se generaría la transformación de los barrios marginales en Bogotá.

Dentro del proyecto Habitarte se planeó el macromural La Mariposa, en relación con el sendero de las mariposas. Este macromural se encuentra ubicado en la UPZ de San Cristóbal Norte, parte oriental de la localidad de Usaquén (condensa siete barrios: Santa Cecilia I, Arauquita, Arauquita II, Urbanización Santa Cecilia Parte Alta, Perla Oriental, Villa Nidya y Cerros del Norte). Estos barrios son de estratos uno y dos, y sufren problemáticas de "consumo y tráfico de sustancias psicoactivas; altos niveles de informalidad; bajos niveles de acceso al emprendimiento y al crédito; baja presencia o ausencia institucional estatal, por lo cual los grupos armados y la delincuencia se toman los sectores" (Ceds2013, s. f.).

El proyecto estaba alineado con otros ejes temáticos que la institucionalidad también planeaba atender y solucionar. La Alcaldía Mayor de Bogotá y la Fundación Orbis Pintuco propusieron el proyecto como eje de cambio y de desarrollo local, con la intervención en procesos sociales de la comunidad. Para el entonces alcalde Enrique Peñalosa, esto sería embellecer la marginalidad, mejorar la seguridad y aumentar el comercio:

Este macromural se convirtió en un símbolo: desde los aviones, la Autopista Norte o la Colina de Suba se puede ver este macromural de La Mariposa, el nuevo símbolo de Bogotá. Este proyecto propició una organización comunitaria, mejoró la seguridad y vino acompañado de otra serie de obras muy grandes como: acueducto y alcantarillado, pavimentos y parques. Ahora este mural comienza a ser atractivo, ya que por aquí pasará el sendero de Las Mariposas, que irá desde Chía hasta Usme, lo que servirá para que haya restaurantes, cafeterías, panaderías, etc., logrando darles más identidad a los barrios que hacen parte de La Mariposa (Radio Santa Fe, 2019).

\section{La mirada de La Mariposa}

Como parte del proceso de identificar qué se quiso comunicar con la gráfica urbana del proyecto Habitarte se realizó un trabajo de campo y entrevistas a residentes del sector, con el fin de analizar la labor colaborativa de la comunidad, qué percepción tienen sobre la gráfica urbana y cómo la asumen; en otras palabras, como lo explican Vargas y Goodfellow (2014), esa gráfica urbana, entendida como "una forma de comunicación propia que refleja su cultura" (2014, p. 39). 
Fotografía 1. Entrada a La Mariposa

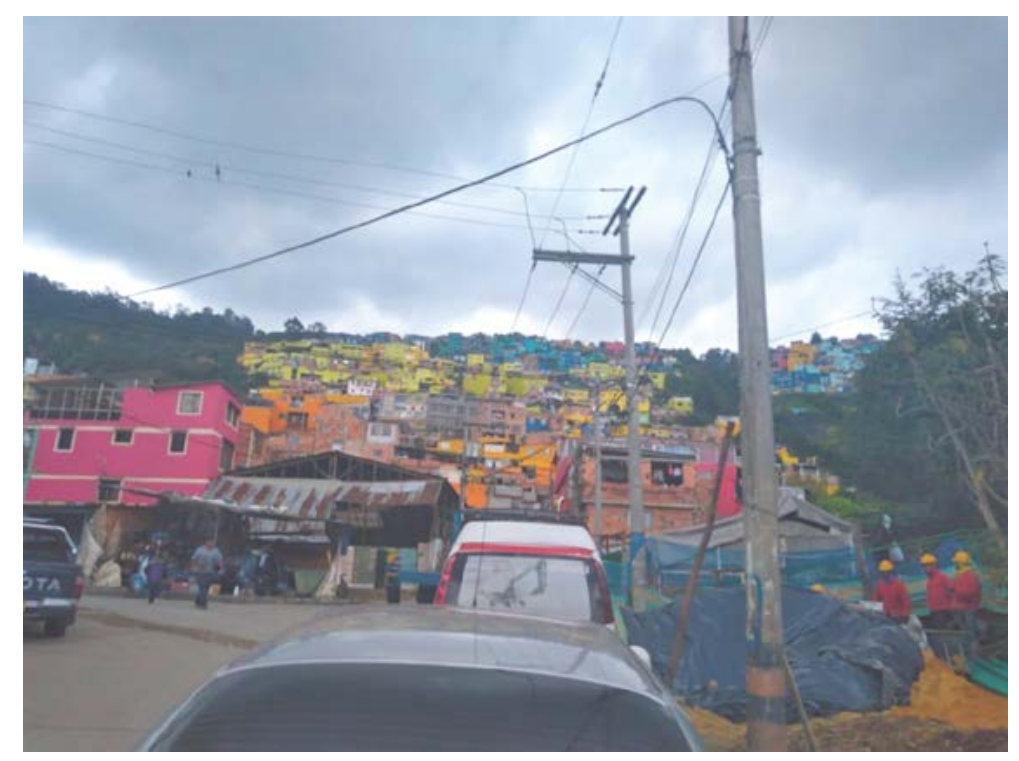

Fuente: Fotografía tomada por la autora.

Al llegar a la entrada de La Mariposa (carrera $6 .{ }^{a}$ con diagonal 162) no hace falta subir tanto para encontrar mujeres y hombres que salen con escobas de sus casas para limpiar sus fachadas y andenes. Comentan que quieren ver sus casas y cuadras en buen estado. Desde el principio, el paisaje gráfico abunda, pero son pocas las personas que se detienen a ver los murales y las que lo hacen solo paran por unos segundos.

Dentro de los barrios de La Mariposa no todas las casas están pintadas ni tienen murales. Algunos dicen que no quisieron pintarlas del color que les dijeron y otras que sí querían, pero que no alcanzó la pintura. A la hora de hablar de cómo se relacionan con el entorno y qué consideran que les comunica toda la gráfica urbana del barrio, hay posturas muy alineadas. A algunos entrevistados los murales les hacen sentir y revivir constantemente su historia; otros no entienden qué relación tienen con el entorno (un tema de análisis relevante para la comunidad que se quiere destacar en estas líneas).

Uno de esos murales que la comunidad siente representativo se llama Maizales y ha sido replicado: 
Fotografía 2. Mural Maizales

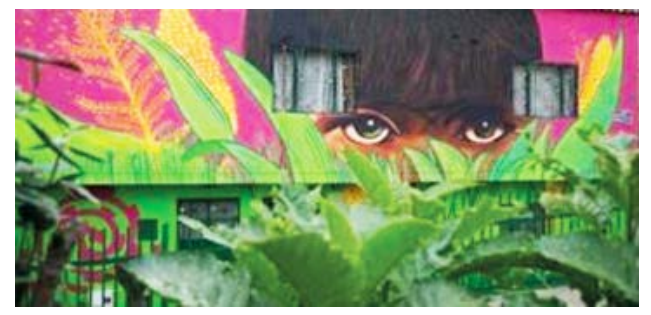

Fotografía 3. Mural La mujer y la cosecha

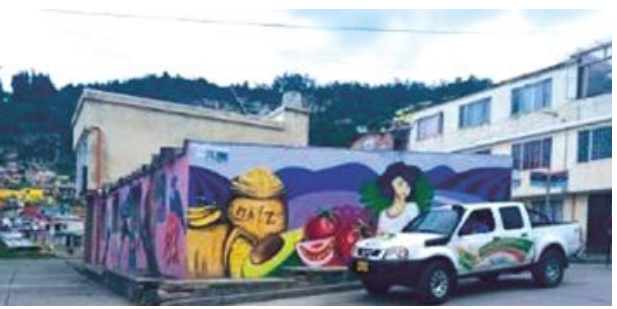

Fuente: Fotografías tomadas por la autora.

Estos murales los representan porque las familias que fundaron los primeros barrios en La Mariposa eran de Cundinamarca, Boyacá y Santander, y para ellos el maíz fue primordial en la alimentación. Hoy en día, de hecho, llevan a cabo una Feria del Maíz, en la cual todos los alimentos deben estar basados en este grano fundamental. Julián Salamanca, un joven trabajador de La Mariposa, considera que esos murales les hacen recordar cómo llegaron al territorio y que el maíz los une como comunidad.

También hay varios murales sobre las comunidades indígenas y campesinas, un tributo a las primeras familias que poblaron el territorio; estos murales comunican su historia. Varios entrevistados afirmaron que ya había unos sobre dichas comunidades antes del proyecto Habitarte, pero en el proceso de trabajo colaborativo, la comunidad le pidió a la Alcaldía replicar su historia en las paredes de sus barrios.

Fotografía 4. Mural Hombre indígena

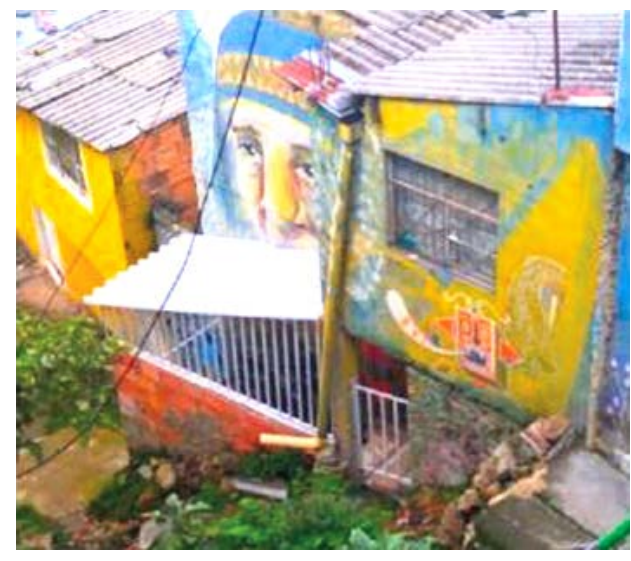

Fotografía 5. Mural Mujer campesina

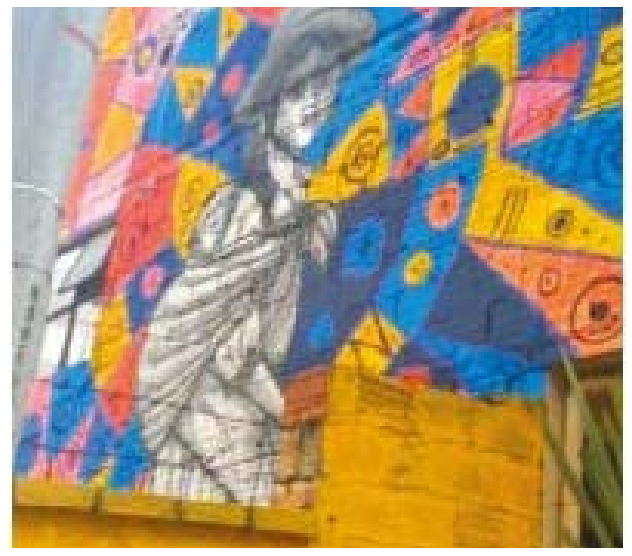

Fuente: Fotografías tomadas por la autora. 
Según manifestaron algunos miembros de la comunidad, hay murales con los cuales no se sienten identificados. La Alcaldía de Bogotá y Orbis Pintuco querían resaltar la biodiversidad, pero para los residentes, El faisán, El mandela, El búho y otros murales sobre pájaros no tienen gran relación con la comunidad ni con su historia; los consideran bonitos, mas no entienden qué es lo que representan.

Fotografía 6. Mural El faisán

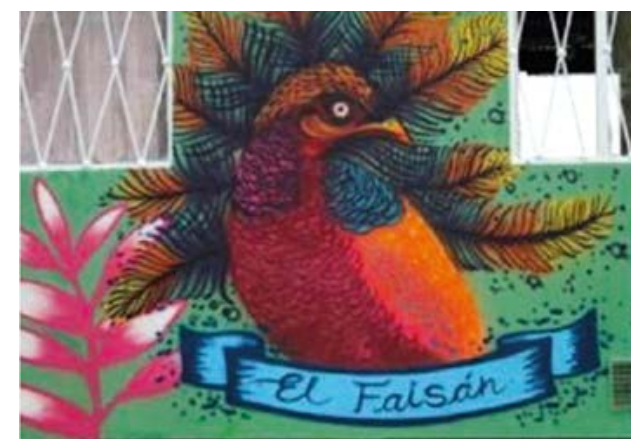

Fotografía 7. Mural El pájaro

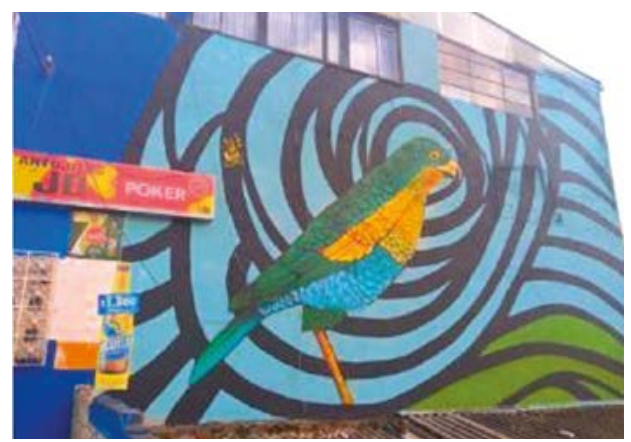

Fuente: Fotografías tomadas por la autora.

Este es el punto de reflexión más destacado en las entrevistas. Para los entrevistados, es una labor artística de muy buena calidad, pero, reiteran, no se sienten representados: más allá de lo estético, no ven la historia del barrio contada allí. Este tipo de procesos evidencian la intención de determinar una estética similar con otros proyectos del distrito, referente aquella a la naturaleza y a la biodiversidad. Se trata de la visibilización de un rol hegemónico de quien cuenta la historia frente a las dinámicas de lo subalterno y lo que este quiere narrar.

Algunos entrevistados consideraron que la razón de lo anterior es volver el lugar más turístico; por tanto, no están hechos para ellos, sino para los que vienen de afuera. Les preocupa que estén diseñando para ocultar las realidades de los barrios y las historias que querían comunicar. Se presenta aquí, entonces, una despolitización de los espacios: no desconocen su orgullo por la variedad de murales del sector, pero los sienten ajenos.

la carta de demanda de las comunidades, un proceso de resistencia cultural propia, la oportunidad de narrar sus historias y de generar un lenguaje. Esto explica el hecho de que los habitantes no se sientan representados en los murales mencionados. 
grande con la comunidad, pero que este tipo de proyectos solo los ha visto en barrios populares, como si quisieran romantizar la pobreza". Uno de los grafiteros que estuvo en parte del proyecto Habitarte (DJ Lu) afirmó que la mayoría de los macro- y micromurales son...

... caras, animales, personajes lavados de cualquier significado o intención política o crítica. Y está bien, eso también es una parte importante del arte urbano en Bogotá, pero no deja de ser paradójico que en los barrios en los que se sufre más la inconformidad con las instituciones, y en los que menos hay espacios de opinión pública, hasta el grafiti esté vetado de ser un espacio libre y público de opinión (Vice, 2018).

El proyecto Habitarte, desde la mirada de los habitantes de La Mariposa, dejó un impacto relevante en el trabajo colaborativo de la comunidad. Eso sí, no comprenden por qué tienen murales que no dicen nada sobre lo que ellos querían expresar de su entorno y que, de hecho, comunicaron al comienzo del proceso creativo.

Estas tensiones presentadas en el ámbito popular terminan siendo la lucha entre los dominantes y los dominados frente a la identidad, a los símbolos y a lo que se quiere comunicar en el entorno. Como lo explica Stuart Hall (1984):

Hay una lucha continua y necesariamente irregular y desigual por parte de la cultura dominante, cuyo propósito es desorganizar y reorganizar constantemente la cultura popular; encerrar y confinar sus definiciones y formas dentro de una gama más completa de formas dominantes. Hay puntos de resistencia; hay también momentos de inhibición. Esta es la dialéctica de la lucha cultural (1984, p. 5).

El manejo que la institucionalidad les da a los espacios es una lucha de resistir y resignificar: aquello que el distrito y la empresa privada quieren encerrar y determinar y lo que la comunidad quiere expresar. La comunicación de la gráfica urbana y popular en principio queda confinada por una estética oficial, pero el entorno popular siempre tendrá la opción de resignificar sus espacios.

La intención de este texto no ha sido criticar el trabajo urbano de los artistas ni el trabajo comunitario, que, como lo explica DJ Lu, también forma parte del conglomerado del arte urbano en Bogotá; el propósito es atender y entender las dinámicas de la institucionalidad en el arte de lo popular, en la lucha continua de resistencia frente a esa dialéctica cultural que pone en jaque todo el tiempo la relación con el entorno y las dinámicas de los dominantes contra lo subalterno. 
Aunque está la idea de ocultar la intención política de estos espacios, eso que se quiere ocultar también está allí expresando las dinámicas de la ciudad, de lo estético como oficial y de lo no oficial. Como lo explica Popular de Lujo (2011), la gráfica urbana ha creado una radiografía de las ciudades que ha ayudado a entender qué es lo que se quiere decir, lo que se quiere cambiar, ocultar o disfrazar.

Finalmente, además de la intencionalidad de los murales, es importante resaltar los procesos de comunicación, sus realidades y las múltiples prácticas que asumen para contar. Desde no permitir que pinten su casa hasta analizar la imagen, el dibujo y la pintura que cuentan la historia, cómo la cuentan y, también cómo la ocultan, para quién se creó y quién la consume.

\section{Referencias}

Ceds2013. (s. f.). Comunidades de Aprendizaje Mutuo para el Desarrollo UPZ San Cristóbal Norte parte Oriental Localidad de Usaquén Bogotá D. C. https: / ceds2013.wordpress. $\mathrm{com} /$ territorio/

Chaparro, E. (2011). Itinerarios de la gráfica popular. Usos, prácticas y sentidos en el espacio urbano. Educación y Ciencia, 12, 77-95.

Cortés, L. (2017). Arte urbano-muralismo en Bogotá. Una aproximación a los procesos de aprendizaje en sus colectivos [PDF]. https: / / repository.uniminuto.edu/bitstream / handle/10656/6012/TECE_CortesCamargoLudby_2017.pdf? sequence=1\&isAllowed=y

García Canclini, N. (1990). Culturas híbridas. Estrategias para entrar y salir de la modernidad [PDF]. Grijalbo. https://monoskop.org/images/7/75/Canclini_Nestor_Garcia_Culturas_ hibridas.pdf

Hall, S. (1984). Notas sobre la desconstrucción de "lo popular" [PDF]. En R. Samuel (Ed.), Historia popular y teoría socialista. Editorial Crítica. http: / www.ram-wan.net/restrepo/ hall/notas\%20sobre\%20la\%20deconstruccion\%20de\%20lo\%20popular.pdf

Popular de Lujo. (2011). Engalle, devoción y porquería: dichosos los ojos que los ven [issuu]. https: / / issuu.com/patrimoniobogota/docs/popdelux_msodbta

Radio Santa Fe. (2019). Sector de La Mariposa promete ser un nuevo símbolo de Bogotá. Radio Santa Fe. https://www.radiosantafe.com/2019/09/09/sector-de-la-mariposapromete-ser-un-nuevo-simbolo-de-bogota/\#: :text=La\%20Mariposa\%20m\%C3\%A1s\%20 grande\%20del, barrios\%20que\%20conforman\%20este\%20secto

Tapia Jáuregui, T. (2018, agosto 16). El problema de querer combatir la pobreza con pintura en Bogotá. Vice. https://www.vice.com/es/article/bjbbqq/el-problema-de-querercombatir-la-pobreza-con-pintura-en-bogota

Vargas, S. y Goodfellow, C. (2014). Antecedentes gráfica popular costarricense. En Gráfica popular costarricense (pp. 31-46). Roger Union Printing. 